\title{
Psychogenic non-epileptic seizures: so-called psychiatric comorbidity and underlying defense mechanisms
}

This article was published in the following Dove Press journal:

Neuropsychiatric Disease and Treatment

30 September 2015

Number of times this article has been viewed

\author{
Massimiliano Beghi ${ }^{1,2}$ \\ Paola Beffa Negrini' \\ Cecilia Perin ${ }^{1,3}$ \\ Federica Peroni ${ }^{1,3}$ \\ Adriana Magaudda ${ }^{4}$ \\ Cesare Cerri ${ }^{1,3}$ \\ Cesare Maria Cornaggia ${ }^{1,3}$ \\ 'Department of Surgery and \\ Translational Medicine, University \\ of Milano-Bicocca, ${ }^{2}$ Department \\ of Mental Health, "Guido Salvini" \\ Hospital, Garbagnate Milanese, \\ Milan, Italy; ${ }^{3}$ Rehabilitation Medicine, \\ Istituti Clinici Zucchi, Carate Brianza, \\ Monza and Brianza, Italy; ${ }^{4}$ Epilepsy \\ Center, Department of Neuroscience, \\ University of Messina, Messina, Italy
}

Correspondence: Massimiliano Beghi Department of Mental Health, "Guido Salvini” Hospital, Garbagnate Milanese, via San Tommaso d'Aquino 2, 20017, Rho, Milan, Italy

Email mbeghi@aogarbagnate.lombardia.it

\begin{abstract}
In Diagnostic and Statistical Manual of Mental Disorders, fifth edition, psychogenic non-epileptic seizures (PNES) do not have a unique classification as they can be found within different categories: conversion, dissociative, and somatization disorders. The ICD-10, instead, considers PNES within dissociative disorders, merging the dissociative disorders and conversion disorders, although the underlying defense mechanisms are different. The literature data show that PNES are associated with cluster B (mainly borderline) personality disorders and/ or to people with depressive or anxiety disorders. Defense mechanisms in patients with PNES with a prevalence of anxious/depressive symptoms are of "neurotic" type; their goal is to lead to a "split", either vertical (dissociation) or horizontal (repression). The majority of patients with this type of PNES have alexithymia traits, meaning that they had difficulties in feeling or perceiving emotions. In subjects where PNES are associated with a borderline personality, in which the symbolic function is lost, the defense mechanisms are of a more archaic nature (denial). PNES with different underlying defense mechanisms have different prognoses (despite similar severity of PNES) and need usually a different treatment (pharmacological or psychological). Thus, it appears superfluous to talk about psychiatric comorbidity, since PNES are a different symptomatic expression of specific psychiatric disorders.
\end{abstract}

Keywords: epilepsy, PNES, defense mechanisms, comorbidity

\section{Historical background}

Historically, phenomena of functional etiology were of relevant interest in the context of phenomenological psychiatry and were described as hysterical phenomena, recognizing for as a specific psychopathological dimension. ${ }^{1}$ Until the advent of dynamic psychiatry, epileptic seizures (ES) and psychogenic non-epileptic seizures (PNES) were considered nearly the same, since it was not possible to distinguish between them, either on the level of instrumental evidence, or on the phenomenological level of the symptom manifestations. PNES differ from ES for some clinical signs but in most cases, a clinical distinction is not possible (Table 1).

Only with the growth of magnetism works, came the first "scientific" distinction between ES and PNES. In 1870s, at the school of Salpêtrière, Charcot ${ }^{2}$ seemed able to distinguish between ES and PNES, and the possibility to achieve the disappearance of the symptoms, or at least an improvement using hypnotic practice.

In France, Charcot $^{2}$ and later Babinski, ${ }^{3}$ focused their research on hysteria, stating that hysteria was a psychic state which made the subject capable of autosuggestion; therefore, hysterical symptoms may (unlike nervous system disorders) be triggered in the patient by suggestion (phenomena called "pithiatic"). 
Table I Signs used to distinguish between psychogenic non-epileptic seizures (PNES) and epileptic seizures (ES)

\begin{tabular}{|c|c|c|}
\hline Variable & PNES & ES \\
\hline Length & Usually $>2$ minutes & Usually $<2$ minutes \\
\hline Onset & Usually gradual & Usually sudden \\
\hline Trigger (light, sound) & Common & Uncommon \\
\hline Location & Usually at home & Variable \\
\hline Asyncronous movement of limbs & Common & Rare \\
\hline Side to side head movement & Common & Rare \\
\hline Side tongue bite & Rare & Common \\
\hline Scream & Common & Only at the beginning \\
\hline Cianosis & Rare & Common \\
\hline Postictal confusion & Rare & Common \\
\hline Eyelid closure & Very common & Rare \\
\hline Eyelid opening resistance & Very common & Rare \\
\hline Hurt & Rare & Common \\
\hline
\end{tabular}

The traumatic origin was initially supported by Breuer and Freud's "seduction theory", but the same authors later considered PNES as complex issues in which biological thrusts and emotional factors were involved and connected. ${ }^{4}$ An instability of the ego (theory of Pierre Janet ${ }^{5}$ ), a strong predisposition of the female sex, the presence of a secondary benefit, and the so-called "belle indifference" were specific for the hysteria.

PNES are actually considered paroxysmal and involve involuntary attacks or behavioral changes characterized by sudden and temporary alteration of motor, sensory, autonomic, cognitive, and emotional control, whose critical content is similar to those observed during ES, but without electrical alterations or pathological modifications of the electroencephalography. ${ }^{6}$ The PNES are in fact a nonintentional expression of emotional distress. ${ }^{7}$ The semiology of these attacks is various: generalized movements, either tonic (stiffness), clonic or dystonic, absence of movement (akinesia), falling, focal motor movements or experiential phenomena reported by the patients (fear, anxiety, dreamy state, paresthesia, etc); nevertheless, a universally accepted classification has not been done yet.

Due to their similarity to ES, those phenomena that were similar to ES but did not have the same electrophysiological etiology, were labeled simply as "non-epileptic seizures" without further investigation, and relegated to a care setting that was foreign to the neurologist and poorly understood by the psychiatrist, confined in a sort of "land of anyone".

Concerning the nosography, after the transition from the Diagnostic and Statistical Manual of Mental Disorders (DSM)-II to DSM-III, the terms "neurosis" and "hysteria" disappeared. Symptoms were broken up to their individual phenotypes and deprived of their meaning into experience and history of the subject. ${ }^{8}$ After the publication of DSM-IV $\mathrm{TR},{ }^{8}$ the classification of PNES no longer has found a unique and proper place as they are distributed in different categories: conversion, dissociative, and somatization disorders. In a recent small study, ${ }^{9} 63 \%$ of patients were diagnosed with conversion disorder, $19 \%$ with somatization disorder, $7 \%$ with dissociative disorder not specified, $7 \%$ with posttraumatic stress disorder (PTSD), and $4 \%$ with undifferentiated somatoform disorder. PNES are likely to be confused with a framework which "could be epilepsy but is not", and therefore be relegated to a lower level tagged as a comorbidity of something else. In the DSM-5, ${ }^{10}$ the theoretical point of view has changed a lot; the new classification of "somatic symptoms and related disorders" defines the major diagnosis on the basis of positive symptoms (distressing somatic symptoms plus abnormal thoughts, feelings, and behaviors in response to these symptoms). However, unexplained medical symptoms remain a key feature in conversion disorder and PNES do not have the specific place where they are needed yet. Stone et $\mathrm{al}^{11}$ supported the current DSM classification affirming that the arguments in favor of splitting off PNES from other neurological symptoms are not as strong as keeping them together (wherever they are placed in DSM-5).

The ICD- $10^{12}$ places the PNES in the dissociative disorders, although, unlike the DSM-5, it merges dissociative disorders and conversion disorders even if the underlying defense mechanisms are different.

The risk is to create a "cauldron" where every different manifestation, which is rarely understood in their clinical significance and symptomatic expressiveness, is likely to be found together.

The present work intends to assess, due to the current lack of literature, what are the clinical conditions that characterize the phenomena we call PNES could be, particularly in light of the so-called psychiatric comorbidity and the underlying defense mechanisms that are not taken into account in the other studies. 


\section{Psychiatric disorders and PNES: can we talk about comorbidity?}

In the literature, the comorbidity between PNES and other psychiatric disorders is frequent ${ }^{13,14}$ as, in a study conducted by Turner et al, ${ }^{15}$ all patients with PNES had a psychiatric diagnosis. A recent review estimates that the prevalence rate of depression in adults with PNES is between $21 \%$ and $60 \%{ }^{16}$ This rate is higher than in the general population ${ }^{16,17}$ and in patients with ES. ${ }^{16}$ Depression is correlated with a lower level of functioning and to a worse quality of life, ${ }^{17,18}$ although in patients with PNES the quality of life is lower than in patients with ES even without a diagnosis of depression. ${ }^{17}$ The type of depression symptoms seems to differ between PNES patients, who show more physiological symptoms of depression, and ES patients. ${ }^{19}$

The prevalence of anxiety disorders (especially for PTSD) is higher in PNES than in the general population and in drug-resistant epilepsy. ${ }^{20,21}$ More specifically, many patients who have PNES have features of PTSD and $22 \%-100 \%$ of patients with PNES fulfill the DSM-5 criteria for PTSD. ${ }^{22}$ In the patients with comorbid PTSD, the hypomotor semiology seems to be predominant, ${ }^{23}$ as well as in patients with PNES only than in patients with comorbid PNES and ES. ${ }^{24}$ Depression and anxiety ratings are higher in the presence of trauma. ${ }^{25}$ Data on psychosis are scarce, but the prevalence of psychosis in PNES seems to be the same ${ }^{22}$ or even lower ${ }^{20}$ than in the drug-resistant epilepsy.

Personality disorder (especially of cluster B) seems to be correlated with PNES ${ }^{16,26}$ even more than depression and anxiety. ${ }^{27}$ Significant differences between patients with PNES and patients with ES and healthy controls were found in two recent cohort studies in cluster B personality disorders (but not in depression and anxiety disorders). ${ }^{15,28}$

Two studies comparing the Personality Assessment Inventory (PAI) patients with PNES and patients with ES and healthy controls showed more disorders of the subscales related to somatization disorders and conversion disorders in patients with PNES. ${ }^{29,30}$ Similarly, a significant difference was detected in somatic subscales with the Minnesota Multiphasic Personality Inventory (MMPI) between patients with PNES and patients with insomnia. ${ }^{31}$

All these findings are summarized in Table 2.

\section{Defense mechanisms}

Defense mechanisms are unconscious psychological tools that are useful in maintaining the intrapsychic balance of the subject, especially, though not exclusively, in situations with deep anxiety or stress. According to the structural model, defense mechanisms are totally unconscious processes activated by the ego under the pressure of anxiety to prevent the trauma recall and the emergence of instinctual wishes not satisfactory on a conscious level. In case of traumatic or hardto-manage contents, the individual can develop a defense mechanism to avoid contact with this type of experiences that may reactivate painful sensations or memories; this is a normal psychological procedure, as it leads to the individual's self-preservation and to a beneficial adaptation. However, if there is a separation between the affective and emotional content and the consciousness, a nonadaptive behavior can lead to the rise of pathological states.

\section{Archaic and advanced defense mechanisms}

The defense mechanisms can be classified hierarchically according to the degree of maturity associated with them. Anna Freud ${ }^{32}$ was the first who tried to classify the defense mechanisms according to the hierarchical model that took into account the stages of development. She concluded that defense mechanisms have their chronological order, established relationships with other ego functions, and can be directed in the adaptive or pathological sense, if they are used before the right age or kept too long thereafter. For the classical psychoanalytic model, the mental illness is an expression of a conflict between instincts and various psychic structures, and all defense mechanisms have to protect the ego against instinctual demands of the id. ${ }^{33}$

According to the modern classification, ${ }^{34}$ defense mechanism is divided into more "mature" (altruism, sublimation, and humor), "neurotic" (repression, moving, reaction formation, affect isolation, undoing, somatization, and conversion), and more "immature", related to more severe disease states, such as psychosis and personality disorders (splitting, projection, introjection, and denial).

\section{Horizontal split: repression}

Repression is the main neurotic type defense mechanism, whose fundamental purpose is to block the emergence and discharge of instinctual demands that are not acceptable and thus are the sources of distress. It implies a horizontal split, which means that the conscious content remains above the unconsciousness and a barrier that blocks unacceptable contents separates these two parts; in cases of pathological states, there may be a "return of the repressed" and therefore the flooding of unconscious contents that overwhelm the subject's internal barriers. Freud reported about "dynamic unconscious", which means the transition of mental contents on an unconscious level that could be explored only through some specific tools, such as hypnosis or free associations. In the repression, ideas disappear but affections remain. ${ }^{35}$ 


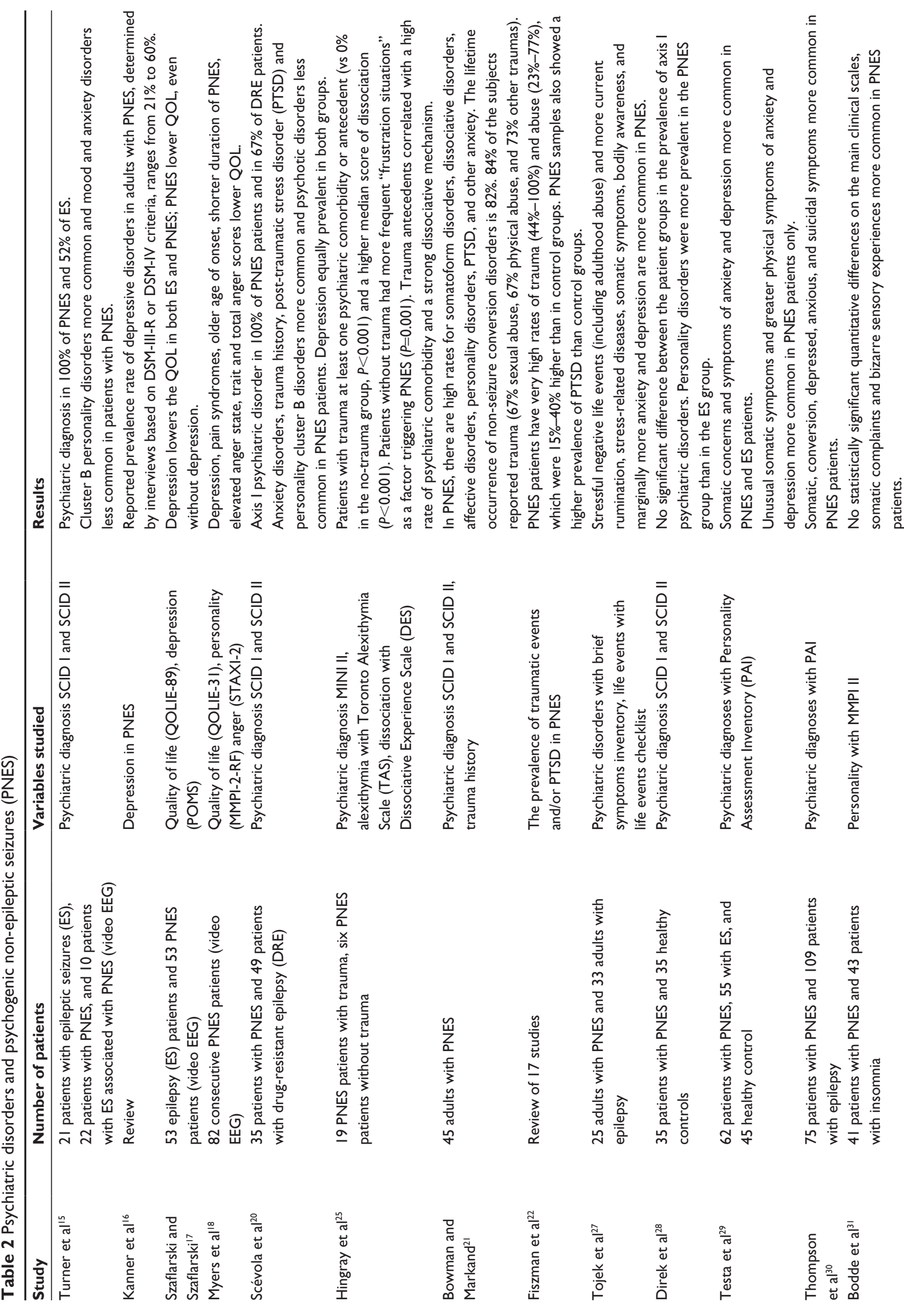



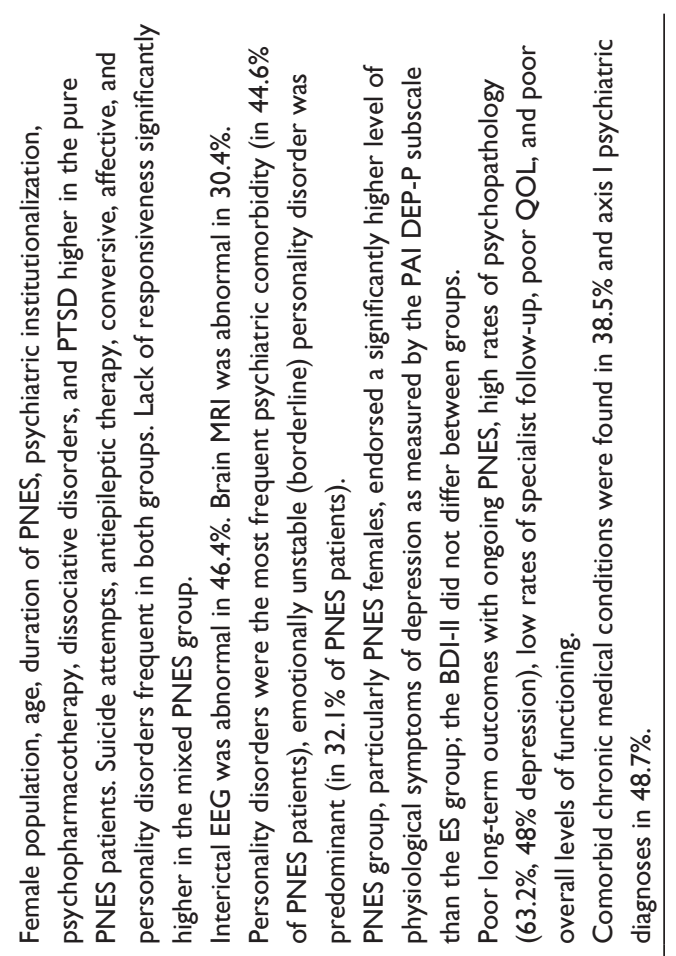

Personalities characterized by the repression mechanisms present a childlike aspect: their emotional experience tends to remain dispersed and labile, their actions are dominated by impulses, and their interpersonal relationships are characterized by unstable attachment. The way of thinking of neurotic subjects is "simplistic", full of affection, and dominated by stereotypes. Krohn ${ }^{36}$ pointed out that the hysterical personalities are prone to use the defense posture of not-knowing, not-seeing, and not-acknowledging.

In conversion disorders, the somatic symptom represents the symbolic resolution of a psychological conflict and leads to avoidance of internal conflict. There are somatic manifestations that lack medical justification, but that cause the same invalidity in relational and social aspects.

\section{Vertical splitting: dissociation}

The DSM- $5{ }^{10}$ defines dissociation as "a disruption of and/ or discontinuity in the normal integration of consciousness, memory, identity, emotion, perception, body representation, motor control, and behavior". The somatoform dissociation $^{37}$ is supposed to be the core element of the newly defined "somatic symptom and related disorder". Nijenhuis ${ }^{37}$ makes a distinction between "psychological dissociation" and "somatoform dissociation". Somatoform dissociation designates dissociative symptoms are those that phenomenologically involve the body, and psychological dissociative symptoms are those that phenomenologically involve psychological variables. Results from the literature pointed out that although somatoform and psychological dissociations are manifestations of a common process, they are not completely overlapping. ${ }^{37}$ Moreover, the repression described in the "Horizontal split: repression" section differs from both psychological and somatoform dissociations because in the latter, there is a vertical splitting. The traumatic contents are not relegated in the unconscious, but they can "exist in parallel in a kind of co-awareness separated by a dissociative barrier".$^{38}$ In the dissociation, contents are not relegated in the unconscious, but they are localized in the preconscious and are accessible to awareness.

Unlike what happens in the repression (in which the representative is removed, while the affection persists), in the dissociation, both idea and affection remain unconscious, but at the same time, they are expressed through alteration of consciousness.

The dissociation includes phenomena such as memory loss in amnesia, loss of awareness in figure states, and division of roles in multiple personality disorder. The common 
denominator is the disappearance of a unitary self and a fragmentation that brings profound anxiety. The dissociation seems to have an adaptive value as a response to severe trauma, and especially in children, it would allow an escape from a highly conflicting situation. The dissociation would work then to preserve the healthy core of the self.

Because of the characteristics of strong reality distortion that can get to the point of not recognizing external events as part of their own experience, Lerner ${ }^{38}$ affirms that "dissociation corresponds to the denial of low-level rather than neurotic level denial". It is observed usually in psychotic states in which a disconnection from reality is present. In PNES, dissociation seems to be correlated with psychiatric comorbidity ${ }^{25,39}$ and with somatization. ${ }^{40}$ However, dissociation could be significantly higher in PNES patients without a comorbid psychiatric disorder too. Recent studies on functional connectivity found stronger connectivity values between emotion (insula), executive control (inferior frontal gyrus and parietal cortex), and movement areas (precentral sulcus) in patients with PNES (without psychiatric comorbidity) than in healthy controls $\mathrm{s}^{41,42}$ and that this connectivity is correlated with high dissociation scores. ${ }^{41,42}$

\section{The defense mechanisms in relation to the PNES}

Patients with PNES are often related closely to subjects with "hysterical" type disorders (somatization and conversion), and are often correlated with anxious or depressive disorders. In these cases, the symbolic function is preserved, as patients use defensive mechanisms belonging to the neurotic register as repression, reactive formation, retroactive annulment, displacement, and affect isolation. ${ }^{34}$ Defense mechanisms belonging to the so-called "Style 1" are not excluded and indicate a more regressive situation linked to the inability to integrate pulses, such as autistic withdrawal, acting out, inhibition, passive aggression, and projection. ${ }^{43}$

The majority of patients with PNES have alexithymia traits, meaning that they had difficulties in feeling or perceiving emotions. ${ }^{7,25,44,45}$ The role played by the bodily expression of the disorder, as well as the presence of a repression process that drives most disturbing elements in the unconscious (tendency to minimize the critical event and to focus attention more on the context), is undeniable.

Various studies that used conversational approach in the differential diagnosis between ES and PNES ${ }^{46-48}$ showed that individuals with PNES are very vague, while people with ES are very precise in the description of seizures, with an attempt to overcome the gap, or interruption of the existential continuum. This further shows the "functionality" of this gap inside a defense mechanism, whose aim is to lead to a split, either vertical or horizontal. In the stories of individuals with PNES, the gap is maintained, even if they do not actually lose consciousness, their descriptive effort is directed fully to the context, which is addressed to their symptomatic and bodily message. By contrast, in patients with ES, even in front of a loss of consciousness, the effort is all about the story reconstruction, even imaginary, of the gap, because they experienced the seizure as intrusive and unexpected. ${ }^{49}$

In subjects whose PNES are associated with a borderline personality structure, in which the symbolic function is lost or significantly damaged, the defense mechanisms are not only archaic in nature for mainly dissociation (which reconnects to primitive idealization), but also denial, omnipotence, devaluation, and the split. ${ }^{34}$ According to Bond, ${ }^{43}$ the defensive style of borderline structures could be defined as "Style 2", which is characterized by an image distortion through splitting, primitive idealization, and almighty devaluation. As in the borderline personality disorder, the subject with PNES lives the separation and alternation, almost compartmental, between opposing states of their own experience (presence or absence of seizures) and appeals to denial when the traumatic reality (seizure) is disregarded inside the horizontal split. Even in this case, the narrative experience of not reconstructing the gap is understood.

Patients with PNES can also have different coping strategies. A high emotion-focused coping was seen in patients with underlying psychological symptoms that were not observed in other coping strategies. This information supports the relevance of assessing stress coping in patients with PNES because it allows the identification of useful behavioral targets for the psychotherapist. ${ }^{50}$

For these reasons, PNES with different underlying defense mechanisms need usually a different treatment (pharmacological or psychological). The relationship between the type of PNES and defense mechanism involved has not been studied yet in the literature.

\section{Discussion}

In recent decades, the defense mechanisms are being increasingly considered in their clinical sense, not as mental operation, which have the function to protect from anxiety, but rather as structures specialized in the solution to psychic conflicts $^{51}$ which mediate between desires, needs, feelings, and impulses of the individual, on the one hand, and internal prohibitions and external realities, on the other hand. They, therefore, constitute a creative synthesis, are relatively 
involuntary and unconscious, and can distort internal and/ or external reality. ${ }^{52}$

Bromberg ${ }^{53}$ affirms that "Dissociation, such as repression, is a healthy and adaptive function of the human mind." It is a basic process that allows individual states of the self to work in an optimal way (and not only in a simply defensive way), when we really need or want to have a full immersion in a single reality, a single strong affection, and a suspension of the auto-reflexive ability. In other words, the dissociation is, first and foremost, a means by which a human being keeps personal continuity, consistency, and integrity of the sense of self..$^{53}$

Patients with PNES displayed somatoform dissociation to a greater extent than those with ES, but this difference was not retained when statistically controlling for anxiety scores or demographic and seizure variables. ${ }^{54} \mathrm{~A}$ recent study carried out by Kaplan et $\mathrm{al}^{44}$ compared patients with ES and patients with PNES on their defensive style, using the response evaluation measure, and did not find any difference between the two groups. ${ }^{37}$ In addition, different problems of emotion processing may predominate in the same patient at different points of their disorder. ${ }^{54}$

As suggested by Brown et $\mathrm{al}^{55}$ and Baslet, ${ }^{56}$ at the basis of the etiopathogenic mechanism of PNES and some ES in its expression of "dissociation", there could be the same disconnection of brain areas involved in different cognitive and emotional functions. When either an epileptic or a psychogenic event occurs, there is a "dissociation" of behavioral and attention systems with a "gap" between the usual systems and the symptoms that emerge during the seizure. According to Roberts and Reuber, ${ }^{54}$ neural mechanisms underlying these processes have begun to be explored in PNES, and relevant models have been developed more fully in related states or conditions such as PTSD, dissociation and depersonalization, and borderline personality disorder.

When there is no organic correspondence explaining and justifying some physical states, we enter a field where the presented symptoms convey meanings that have to be interpreted and processed; this definition seems to recall vaguely the one that Freud used to describe the pathology of hysteria.

During the ES, there is a hyperactivation of a specific part of the brain, while the remaining is excluded; in case of complex partial epilepsy, dissociative symptoms may occur because patients during ictal and postictal phases may exhibit wandering or semifinalized behaviors resulting in amnesia; amnesia for the event or feelings of déjà vu, like in epilepsy of the temporal lobe, are also possible phenomena of denial of sensory data.
There is an element that connects the experience of any critical event, being of epileptic or psychogenic etiology (a "split"), between different states of mind awareness.

Both ES and PNES present a dysfunction in emotional processes or to gain from dissociation (in Bromberg meaning $)^{53}$ to cope with a traumatic event.

Not surprisingly, many studies have highlighted that the prevalence of severe traumatic events, such as child sexual or physical abuse, is present in patients with PNES in a percentage that goes from $32.4 \%$ to $88.0 \%$. A history of trauma affects in a negative way alexithymia traits and adherence to psychotherapy. ${ }^{7,45,57}$

There is an attempt to cope with a trauma, trying to depart from it, and not to be disintegrated by it; in the case of PNES, such an attempt is made using the body at a symbolic level. The affection that cannot be verbalized is shown in different ways: more advanced in the case of a neurotic structure and more archaic for the borderline one, where the symbolic level is more lacking.

In PNES, the body is only a vehicle, a medium; the trauma does not originate from the person and his or her manifestations, but from a previous emotional "engorgement" that materializes through the body.

Patients with PNES report more negative life events and they do not indicate them as triggers of their seizures. However, patients with epilepsy correlate more of their negative life events to seizures. ${ }^{7,56}$ In PNES, traumatic experiences are also accompanied by dissociative phenomena, since many of these seizures represent a complete or partial loss of integration of mental functions such as identity, memory, consciousness, and environment perception. From this point of view, the split no longer belongs exclusively to the defense mechanisms, but arises as a process that distinguishes mental states that accompany the human experience, both in its healthy expressions and in its pathological ones, and thus becomes an experience of how the psychic apparatus is structured under certain circumstances.

At this point, we have to do with a framework with its own statute and dignity. PNES are the symptomatic expression of a psychiatric disorder itself, and we should talk about an underlying etiological diagnosis instead of psychiatric comorbidity. The PNES indicate a way to "convert" psychological distress on organic level by replacing the verbal with a representation of symptoms.

The most appropriate part of PNES definition is that of "psychogenic" seizures, as that term encompasses the variety and depth of the exhibited symptoms as well as the types of underlying defense mechanisms. 
Following this trend, traits seem to emerge connected to a disease, apparently disappearing like hysteria, and, therefore, it is almost natural to recall Mattioli and Scalzone ${ }^{58}$ who argued that

[...] the hysterical pathology will never disappear because it represents a specific state of mind, an operational mode, characterized by an psychodynamic organization made up of defense mechanisms, cognitive styles, memory functions, personality traits and psychological and somatic symptoms. ${ }^{58}$

\section{Conclusion}

PNES are the result of differences in brain processes and that of defense mechanisms. Consequently, prognosis and different pharmacological or psychological treatment should be need. Thus, it appears superfluous to talk about psychiatric comorbidity, since PNES are a different symptomatic expression of specific psychiatric disorders.

\section{Disclosure}

The authors report no conflicts of interest in this work.

\section{References}

1. Jaspers K. Allgemeine Psychopathologie. Ein Leitfaden für Studierende, Ärzte und Psychologen [General Psychopathology: A Textbook for Students, Physicians and Psychologists]. Berlin: J. Springer; 1913. German.

2. Charcot JM. Leçons du mardi à la Salpetriere. Policliniques 1887-1889 [Tuesday Lessons at the Salpetriere. Policlinics 1887-1889]. Paris: Bureaux du Progrès Medical; 1889. French.

3. Babinski J. Hystérie-pithiatisme et troubles nerveux d'ordre réflexe en neurologie de guerre [Hysteria or pithiatism: and reflex nervous disorders in the neurology of war]. Paris: Masson;1918.

4. Breuer J, Freud S. Studies in Hysteria. New York: Nervous and Mental Disease Publishing; 1937.

5. Janet P. Les Medications Psychologiques [The Psychology Medications]. Paris: Alcan; 1919-1921. French.

6. Lesser RP. Psychogenic seizure. Neurology. 1996;46:1499-1507.

7. Reuber M. The etiology of psychogenic non-epileptic seizures: toward a biopsychosocial model. Neurol Clin. 2009;27:909-924.

8. American Psychiatric Association. Diagnostic and Statistical Manual of Mental Disorders. Text Revision (DSM-IV-TR). 4th ed. Washington (DC): American Psychiatric Press; 2000.

9. Marchetti RL, Kurcgant D, Neto JG, von Bismark MA, Marchetti LB, Fiore LA. Psychiatric diagnoses of patients with psychogenic nonepileptic seizures. Seizure. 2008;17(3):247-253.

10. American Psychiatric Association. Diagnostic and Statistical Manual of Mental Disorders (DSM-5). 5th ed. Washington (DC): American Psychiatric Press; 2013.

11. Stone J, LaFrance WC Jr, Brown R, Spiegeld D, Levensond JL, Sharpe M. Conversion disorder: current problems and potential solutions for DSM-5. J Psychosom Res. 2011;71(6):369-376.

12. World Health Organization. The ICD-10. Classification of Mental and Behavioural Disorders, Clinical Descriptions and Diagnostic Guidelines. Geneva: WHO Press; 1992.

13. Jones SG, O'Brien TJ, Adams SJ, et al. Clinical characteristics and outcome in patients with psychogenic nonepileptic seizures. Psychosom Med. 2010;72(5):487-497.
14. Seneviratne U, Briggs B, Lowenstern D, D'Souza W. The spectrum of psychogenic non-epileptic seizures and comorbidities seen in an epilepsy monitoring unit. J Clin Neurosci. 2011;18(3):361-363.

15. Turner K, Piazzini A, Chiesa V, et al. Patients with epilepsy and patients with psychogenic non-epileptic seizures: video-EEG, clinical and neuropsychological evaluation. Seizure. 2011;20(9):706-710.

16. Kanner AM, Schachter SC, Barry JJ, et al. Depression and epilepsy, pain and psychogenic non-epileptic seizures: clinical and therapeutic perspectives. Epilepsy Behav. 2012;24:169-181.

17. Szaflarski JP, Szaflarski M. Seizure disorders, depression, and healthrelated quality of life. Epilepsy Behav. 2004;5:50-57.

18. Myers L, Lancman M, Laban-Grant O, Matzner B, Lancman M. Psychogenic non-epileptic seizures: predisposing factors to diminished quality of life. Epilepsy Behav. 2012;25:358-362.

19. Asmussen SB, Kirlin KA, Gale SD, Chung SS. Differences in selfreported depressive symptoms between patients with epileptic and psychogenic nonepileptic seizures. Seizure. 2009;18(8):564-566.

20. Scévola L, Teitelbaum J, Oddo S, et al. Psychiatric disorders in patients with psychogenic nonepileptic seizures and drug-resistant epilepsy: a study of an Argentine population. Epilepsy Behav. 2013;29(1):155-160.

21. Bowman ES, Markand ON. Psychodynamics and psychiatric diagnoses of pseudoseizure subjects. Am J Psychiatry. 1996;153(1):57-63.

22. Fiszman A, Alves-Leon SV, Nunes RG, D’Andrea I, Figueira I. Traumatic events and posttraumatic stress disorder in patients with psychogenic nonepileptic seizures: a critical review. Epilepsy Behav. 2004;5:818-825.

23. Chen DK, Izadyar S. Characteristics of psychogenic nonepileptic events among veterans with posttraumatic stress disorder: an association of semiology with the nature of trauma. Epilepsy Behav. 2010;17(2): 188-192.

24. D'Alessio L, Giagante B, Oddo S, et al. Psychiatric disorders in patients with psychogenic non-epileptic seizures, with and without comorbid epilepsy. Seizure. 2006;15(5):333-339.

25. Hingray C, Maillard L, Hubsch C, et al. Psychogenic nonepileptic seizures: characterization of two distinct patient profiles on the basis of trauma history. Epilepsy Behav. 2011;22:532-536.

26. Hovorka J, Nezádal T, Herman E, Nemcová I, Bajacek M. Psychogenic non-epileptic seizures, prospective clinical experience: diagnosis, clinical features, risk factors, psychiatric comorbidity, treatment outcome. Epileptic Disord. 2007;9(Suppl 1):S52-S58.

27. Tojek TM, Lumley M, Barkley G, Mahr G, Thomas A. Stress and other psychosocial characteristics of patients with psychogenic nonepileptic seizures. Psychosomatics. 2000;41(3):221-226.

28. Direk N, Kulaksizoglu IB, Alpay K, Gurses C. Using personality disorders to distinguish between patients with psychogenic nonepileptic seizures and those with epileptic seizures. Epilepsy Behav. 2012;23:138-141

29. Testa SM, Lesser RP, Krauss GL, Brandt J. Personality Assessment Inventory among patients with psychogenic seizures and those with epilepsy. Epilepsia. 2011;52:s84-s88.

30. Thompson AW, Hantke N, Phatak V, Chaytor N. The Personality Assessment Inventory as a tool for diagnosing psychogenic nonepileptic seizures. Epilepsia. 2010;51:161-164.

31. Bodde NM, Bartelet DC, Ploegmakers M, Lazeron RH, Aldenkamp AP, Boon PA. MMPI-II personality profiles of patients with psychogenic nonepileptic seizures. Epilepsy Behav. 2011;20:674-680.

32. Freud A. The Ego and the Mechanisms of Defense. New York: Indiana University of Pennsylvania; 1966.

33. Freud S. Inhibition, Symptoms and Anxiety. Stamford (CT): Psychoanalytic Institute; 1927.

34. Vaillant GE. Ego mechanisms of defense and personality psychopathology. J Abnorm Psychol. 1994;103:44-50.

35. Freud S. La rimozione [The Repression]. Torino: Bollati Boringhieri; 1915. Italian.

36. Krohn A. Hysteria: The Elusive Neurosis. New York: International Universities Press, Inc.; 1978. 
37. Nijenhuis ERS. Somatoform dissociation: major symptoms of dissociative disorders. J Trauma Dissociation. 2000;1(4):7-32.

38. Lerner P. Psychoanalytic Perspective of the Rorschach. Hillsdale (NJ): Analytic Press; 1998.

39. Baslet G, Roiko A, Prensky E. Heterogeneity in psychogenic nonepileptic seizures: understanding the role of psychiatric and neurological factors. Epilepsy Behav. 2010;17(2):236-241.

40. Bodde NM, van der Kruijs SJ, Ijff DM, et al. Subgroup classification in patients with psychogenic non-epileptic seizures. Epilepsy Behav. 2013;26(3):279-289.

41. van der Kruijs SJ, Bodde NM, Vaessen MJ, et al. Functional connectivity of dissociation in patients with psychogenic non-epileptic seizures. J Neurol Neurosurg Psychiatry. 2012;83(3):239-247.

42. van der Kruijs SJ, Jagannathan SR, Bodde NM, et al. Resting-state networks and dissociation in psychogenic non-epileptic seizures. J Psychiatr Res. 2014;54:126-133.

43. Bond M. Are "borderline defenses" specific for borderline personality disorders? J Personality Disord. 1990;4:251-256.

44. Kaplan MJ, Dwivedi AK, Privitera MD, Isaacs K, Hughes C, Bowman M. Comparisons of childhood trauma, alexithymia, and defensive styles in patients with psychogenic non-epileptic seizures vs epilepsy: implications for the etiology of conversion disorder. $J$ Psychosom Res. 2013;75(2):142-146.

45. Myers L, Matzner B, Lancman M, Perrine K, Lancman M. Prevalence of alexithymia in patients with psychogenic non-epileptic seizures and epileptic seizures and predictors in psychogenic non-epileptic seizures. Epilepsy Behav. 2013;26(2):153-157.

46. Cornaggia CM, Gugliotta SC, Magaudda A, Alfa R, Beghi M, Polita M. Conversation analysis in the differential diagnosis of Italian patients with epileptic or psychogenic non-epileptic seizures: a blind prospective study. Epilepsy Behav. 2012;25:598-604.

47. Reuber M, Monzoni C, Sharrack B, Plug L. Using interactional and linguistic analysis to distinguish between epileptic and psychogenic nonepileptic seizures: a prospective, blinded multirater study. Epilepsy Behav. 2009;16:139-144.
48. Schwabe M, Howell SJ, Reuber M. Differential diagnosis of seizure disorders: a conversation analytic approach. Soc Sci Med. 2007;65(4): $712-724$.

49. Holman N, Kirkby A, Duncan S, Brown RJ. Adult attachment style and childhood interpersonal trauma in non-epileptic attack disorder. Epilepsy Res. 2008;79(1):84-89.

50. Myers L, Fleming M, Lancman M, Perrine K, Lancman M. Stress coping strategies in patients with psychogenic non-epileptic seizures and how they relate to trauma symptoms, alexithymia, anger and mood. Seizure. 2013;22(8):634-639.

51. Dazzi N, De Coro A. Psicologia Dinamica. Le teorie cliniche [Psychodynamic Psychotherapy. The Clinical Theories]. Roma-Bari: Laterza; 2001. Italian.

52. Lingiardi V, Madeddu F. I meccanismi di difesa: teoria clinica e ricerca empirica [Defense Mechanisms: Theory, Assessment, Practice] Milano: Raffaello Cortina; 2002. Italian.

53. Bromberg P. Standing in the Spaces. Hillsdale (NJ): Analytic Press; 1998.

54. Roberts NA, Reuber M. Alterations of consciousness in psychogenic nonepileptic seizures: emotion, emotion regulation and dissociation. Epilepsy Behav. 2014;30:43-49.

55. Brown RJ, Syed TU, Benbadis S, La France WC, Reuber M. Psychogenic nonepileptic seizures. Epilepsy Behav. 2011;22:85-93.

56. Baslet G. Psychogenic non-epileptic seizures: a model of their pathogenic mechanism. Seizure. 2011;20:1-13.

57. Reuber M. Psychogenic nonepileptic seizures: answers and questions. Epilepsy Behav. 2007;12:622-635.

58. Mattioli G, Scalzone F, editors. Attualità dell'isteria (malattia desueta o posizione originaria) [Actuality of Hysteria (Uncommon Illness or Original Position)]. Milano: FrancoAngeli; 2002.
Neuropsychiatric Disease and Treatment

\section{Publish your work in this journal}

Neuropsychiatric Disease and Treatment is an international, peerreviewed journal of clinical therapeutics and pharmacology focusing on concise rapid reporting of clinical or pre-clinical studies on a range of neuropsychiatric and neurological disorders. This journal is indexed on PubMed Central, the 'PsycINFO' database and CAS,

\section{Dovepress}

and is the official journal of The International Neuropsychiatric Association (INA). The manuscript management system is completely online and includes a very quick and fair peer-review system, which is all easy to use. Visit http://www.dovepress.com/testimonials.php to read real quotes from published authors. 